\title{
What Do DDT and Computing Have in Common?
}

W

RITING ON THE $50^{\text {th }}$ Earth Day brings to mind the origins of U.S. environmental movement.

DDTis, of course, Bis(4-chlorophenyl)1,1,1-trichloroethane, perhaps the most effective insecticide ever invented. DDT was used widely with remarkable effectiveness in the 1940s and 1950s to combat malaria, typhus, and the other insect-borne human diseases. Its efficacy was unsurpassed in insect control for crop and livestock production, and even villages and homes. In short, it was a wonder chemical. ${ }^{7}$

Following Rachel Carson's Silent Spring $^{2}$ highlighting DDT's persistent negative environmental effects, including precipitous declines in wildlife and multiple human health problems, Carson's advocacy led to the banning of DDT and the creation of the U.S. Environmental Protection Agency (1970).

DDT and computing both have amazing benefits, but now that I've got your attention, my point is they also both have significant negatives. And, their good doesn't offset their bad. So, in addition to reaping computing's bounty (education, information access, entertainment, commerce, efficiency, and more), we should "own" and work to reduce the negative impacts of computing.

What are computing's negative environmental impacts?

- Carbon emissions of $>500$ million metric tons of $\mathrm{CO}_{2} /$ year

- E-waste of $>50$ million metric tons year

Both are growing fast and need attention! $!^{3}$ Even AI is an exemplar of computing's dual nature-driving remarkable advances whilst driving increased computing carbon emissions. ${ }^{1,4}$

Is this critical? Is it urgent? Climate change is regularly called an existential crisis for humanity. Further, as Greta Thunberg, who led worldwide protests in 2019 that dwarfed all previous environmental rallies, points out-all must do their part to solve our climate challenge.

"I'm just a technologist, what can I do?" Here are some ideas.

Carbon emissions from computing are growing: the hyperscale cloud is the headline driver-with power consumption increasing 6.5-fold from 2010 to 2018, and even faster since $2018 .^{5}$ But cloud computing can become truly carbon neutral, 7x24 hourly matching! The opportunity for this transformation is the rise of low-cost renewable generation in power grids that produces excess supply (Terawatt-hours) of carbon-free power worldwide. Despite the challenge of the volatility of these renewable excesses, research has proven models that "flex" computing in space and time, and thereby produce zerocarbon compute can be scientifically and economically feasible. ${ }^{8}$

For emissions, we should adopt a goal of zero carbon emission computing for operations. To achieve this, we must design applications and workloads and manage resources to time- and spaceshift computing to align with the availability of renewables. This is possible for the cloud, due in no small part to efficient hyperscale datacenters, global scale, and spectacular management and optimization systems! Lest you still consider this idealistic, there is real movement in this direction. ${ }^{6}$

Computing e-waste is growing rapidly with the explosion of IoT, universal Internet access, and 5G networks. We must extend the lifetime of computing hardware-servers and clients - and increase the circularity of the computing economy far beyond the $<20 \%$ of e-waste that avoids landfills today.

For e-waste, we should adopt a goal to double the lifetime of computing hardware, increasing server lifetime far beyond six years for cloud and enterprise computing, and for smartphones as high as eight years. In vertical, global ecosystems controlled by a few players, there are increasing opportunities. In a new NSF OAC project we are working with universities to create an extended ecosystem for servers that combines zero-carbon operation with extended lifetime.

What can software professionals do? Software can be designed and tuned for efficiency and memory size, enabling client devices to remain viable for over eight years. Software upgrades should have as a design goal to avoid driving client hardware obsolescence. For the cloud, software professionals should reengineer applications to be time flexible, adapting the availability of excess renewable energy.

What can hardware professionals do? Designs can be repairable and upgradeable, and complemented by network services for longer life. Products designed for de-manufacture can reduce environmental pollution and enable circular economy. Create and drive circular economy practice-for all computing hardware.

Changing how computing does business is important. If we undertake these goals, our technologies will be both more flexible and more broadly useful. And perhaps we will attract and inspire more young computing professionals!

Happy $50^{\text {th }}$ Earth Day! I'm looking forward to zero-carbon and zero ewaste computing at the $60^{\text {th }}$ in 2030 !

Be safe and be well!

Andrew A. Chien, EDITOR-IN-CHIE F

For references, see page 6 . 


\section{Safety Proposal Points in Same Direction}

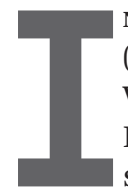
N HER FEBRUARY 2020 column ("Are You Sure Your Software Will Not Kill Anyone?"), Nancy Leveson says the solution to software safety is not "building a software architecture and generating the requirements later." Reading this, we were surprised that anyone would propose such an approach, or that Leveson would find it necessary to argue against it. We were even more surprised to see that Leveson attributes the proposal to a National Academies report that we edited. ${ }^{1}$

Perhaps Leveson had a different report in mind. Our report actually substantiates the very arguments she makes in her column, identifying the same misconceptions that she notes, along with others - and provides citations for the earlier origins of these supposedly new arguments.

Contrary to Leveson's article, however, our report does not take the design as given and claim that "analysis tools can be developed to analyze the safety of complex systems." Rather than treating safety as a quality to be established by an ex post facto analysis, our report calls for the design to be shaped by the safety requirements. Our report's key point is that safety needs a compelling and reasoned argument and that, if the design is constructed with this argument in mind, the credibility of the argument can be increased and the cost of producing it reduced.

Daniel Jackson, Cambridge, MA, USA

Lynette Millett, Washington, D.C., USA

Martyn Thomas, London, U.K.

\section{Reference}

1. D. Jackson, M. Thomas, and L.I Millett, Eds.

Committee on Certifiably Dependable Software

Systems. Software for dependable systems: Sufficient evidence? National Academies Press, 2007.

\section{Author response}

I have reread the NRC report and I was mistaken. I must have confused it with something else I read around the time (probably related to Agile). I am very sorry for my mistake. I should have checked before my column appeared.

Nancy Leveson, Cambridge, MA, USA

\section{Sustainable Charge}

In his February column, Vinton G. Cerf called for more durability from manufacturers and cited Tesla as an example. I would like to suggest that Tesla and other makers of electric cars include with every purchase a garage battery of the same capacity as that in the automobile. The home battery would have suitable programmable switching to enable charging at steady sustainable rate, for example, from renewable resources or overnight, without the wholesale need to strengthen the domestic power grid. This would allow instant vehicle recharging when the driver returns home.

W.B. Langdon, London, U.K.

\section{Response from the Editor-in-Chief}

The temporal misalignment of

renewable electricity generation with load (use) is indeed a growing challenge. In fact, in grids with solar-dominated renewables, such as California, "time of use" rates already favor consumption from morning to mid-afternoon-when an electric car might well be at work, rather than at home! More charging stations at business offices would be a much cheaper solution than redundant batteries for electric cars.

Andrew A. Chien, Chicago, IL, USA

\section{Bleating in Computing Machinery}

I have been a member of the Association for Computing Machinery for over 60 years. Over these three-score years, I have spent a great deal of time adjusting to the machinery in vogue. We first worked hands-on and later used time sharing and a score of other fads. Now we are somewhere in the clouds.

The time has come to call a general meeting of the team. We are not an association of computing machinery; we are an association of individuals concerned about computing. We may have different interests and experience. We work in varied environ- ments. We research many interesting areas of computation. For almost 70 years, ACM has held us in good stead. However, technology has now overwhelmed us. It is and for several years has been moving too fast for all of us.

With the Coronavirus Revolution we now have to work in an environment that is often unreliable, lonely, and depressing.

In a very bleating voice, I cry out for change. We should be called ACP-the Association of Computing Professionals. Let us put it to a vote; 'STAY WITH ACM or MOVE TO ACP.'

Donald F. Costello, Lincoln, NE, USA

\section{Response from the Editor-in-Chief}

It would be difficult to make the argument that ACM isn't well beyond "computing machinery," and I like ACPany other good suggestions? This sounds like just the thing that should be put to ACM Council, and then to a vote by the membership! We have just missed this year's cycle, so plenty of lead time to develop this for next year.

Andrew A. Chien, Chicago, IL, USA

\section{From the Editor-in-Chief, continued from page 5 .}

\section{References}

1. AI for Climate Change, 2020; https://www. climatechange.ai/

2. Carson, R. Silent Spring. Houghton-Mifflin, 1962, ISBN-0618249060.

3. Chien, A.A. Owning computing's environmental impact. Commun. ACM 62, 3 (Mar. 2019)

4. Hao, K. Training a single AI model can emit as much carbon as five cars in their lifetimes: Deep learning has a terrible carbon footprint. Technology Review (June 6, 2019)

5. Masanet, E., Shehabi, A., Lei, N., Smith, S. and Koomey, J. Recalibrating global data center energy-use estimates. Science 367, 6481 (2020) 984-986.

6. Radovanovic, A. Our data centers now work harder when the sun shines and wind blows. Google Data Centers and Infrastructure blog (Apr. 22, 2020); https://bit.ly/2SeEKbE

7. Rogan, W. J. and Chen, A. Health risks and benefits of bis (4-chlorophenyl)-1, 1, 1-trichloroethane (DDT). The Lancet 366, 9487 (2005), 763-773.

8. Yang, F. and Chien, A. Large-scale and extreme-scale computing with stranded green power: Opportunities and costs. IEEE Trans. Parallel and Distributed Systems 29, 5 (May 1, 2018), 1103-1116. 